\title{
Erratum
}

\section{HIV-1 Integrase Inhibitory Phenylpropanoid Glycosides from Clerodendron trichotomum}

\author{
Hyoung Ja Kim1, Eun-Rhan Woo ${ }^{1,2}$, Cha-Gyun Shin', Dong Jin Hwang', Hokoon Park', and Yong Sup Lee \\ ${ }^{1}$ Division of Life Sciences, Korea Institute of Science \& Technology, P.O. Box 131, Cheongryang, Seoul 130-650, \\ Korea, ${ }^{2}$ College of Pharmacy, Chosun University, Kwangju 501-759, Korea and ${ }^{3}$ Department of Biotechnology, \\ Chung Ang University, An-Sung 456-756, Korea
}

Table I. ${ }^{13} \mathrm{C}$ NMR Spectral data of Compounds 1-7 $\left(\mathrm{CD}_{3} \mathrm{OD}\right)$

\begin{tabular}{|c|c|c|c|c|c|c|c|}
\hline C & 1 & 2 & 3 & 4 & 5 & 6 & 7 \\
\hline 1 & 131.6 & 131.5 & 131.6 & 131.4 & 132.9 & 132.9 & 132.7 \\
\hline 2 & 117.2 & 117.1 & 117.2 & 117.1 & 117.1 & 117.1 & 117.0 \\
\hline 3 & 146.1 & 146.1 & 144.7 & 144.7 & 146.9 & 147.4 & 147.5 \\
\hline 4 & 144.6 & 144.6 & 146.1 & 146.1 & 147.4 & 147.6 & 147.3 \\
\hline 5 & 116.4 & 116.4 & 116.6 & 116.5 & 112.9 & 112.9 & 112.8 \\
\hline 6 & 121.4 & 121.3 & 121.2 & 121.2 & 121.2 & 121.2 & 121.1 \\
\hline 7 & 36.6 & 36.7 & 36.6 & 36.7 & 36.6 & 36.6 & 36.7 \\
\hline 8 & 72.3 & 72.4 & 72.1 & 72.3 & 72.1 & 72.1 & 72.4 \\
\hline $1^{\prime}$ & 104.2 & 104.4 & 104.3 & 104.4 & 104.2 & 104.3 & 104.4 \\
\hline $2^{\prime}$ & 76.2 & 75.7 & 76.2 & 75.7 & 76.2 & 76.2 & 75.7 \\
\hline $3^{\prime}$ & 81.7 & 84.1 & 81.5 & 84.0 & 81.7 & 81.5 & 84.1 \\
\hline $4^{\prime}$ & 70.4 & 70.4 & 70.4 & 70.5 & 70.4 & 70.4 & 70.6 \\
\hline $5^{\prime}$ & 75.9 & 75.4 & 76.0 & 75.4 & 76.1 & 76.1 & 75.4 \\
\hline $6^{\prime}$ & 62.4 & 64.7 & 62.4 & 64.7 & 62.4 & 62.4 & 64.7 \\
\hline 1" & 103.0 & 102.7 & 102.9 & 102.7 & 103.1 & 102.9 & 102.8 \\
\hline 2" & 72.4 & 72.4 & 72.4 & 72.5 & 72.4 & 72.4 & 72.4 \\
\hline $3^{\prime \prime}$ & 72.1 & 72.3 & 72.3 & 72.3 & 72.1 & 72.1 & 72.4 \\
\hline 4" & 73.8 & 74.0 & 73.8 & 74.0 & 73.8 & 73.8 & 74.0 \\
\hline 5" & 70.6 & 70.1 & 70.7 & 70.0 & 70.6 & 70.7 & 70.1 \\
\hline $6^{\prime \prime}$ & 18.5 & 17.9 & 18.5 & 17.9 & 18.5 & 18.5 & 17.9 \\
\hline $1^{\prime \prime \prime}$ & 127.7 & 127.7 & 127.7 & 127.6 & 127.7 & 127.7 & 127.4 \\
\hline $2^{1 \prime \prime}$ & 115.4 & 115.2 & 111.9 & 111.6 & 115.2 & 111.9 & 111.6 \\
\hline $3^{\prime \prime \prime}$ & 146.8 & 146.8 & 149.4 & 149.4 & 147.8 & 149.4 & 149.5 \\
\hline $4^{\prime \prime \prime \prime}$ & 149.8 & 149.6 & 150.8 & 150.8 & 149.8 & 150.9 & 151.2 \\
\hline $5^{\prime \prime \prime}$ & 116.6 & 116.6 & 116.4 & 116.3 & 116.5 & 116.6 & 116.6 \\
\hline $6^{1 \prime \prime}$ & 123.3 & 123.2 & 124.4 & 124.3 & 123.2 & 127.7 & 124.4 \\
\hline $7^{\prime \prime \prime}$ & 148.1 & 147.3 & 148.0 & 147.1 & 148.0 & 147.9 & 147.3 \\
\hline $8^{\prime \prime \prime}$ & 114.8 & 114.9 & 115.2 & 115.2 & 114.7 & 115.1 & 115.0 \\
\hline $9^{\prime \prime \prime}$ & 168.4 & 169.2 & 168.4 & 169.1 & 168.3 & 168.3 & 169.2 \\
\hline OMe & & & 56.5 & 56.5 & 56.5 & 56.5 & 56.4 \\
\hline
\end{tabular}

P 289 (Table I $\rightarrow$ Table II) Right column, third line from the bottom 